\title{
Neonatal Gastrointestinal Bleeding, AE
}

National Cancer Institute

\section{Source}

National Cancer Institute. Neonatal Gastrointestinal Bleeding, AE. NCI Thesaurus. Code C154943.

An adverse event in a newborn characterized by hemorrhage originating at any site located within the gastrointestinal tract. 